\title{
EVALUATING QATAR CENTRAL BANK'S GOVERNANCE ON ISLAMIC BANKS IN QATAR
}

\author{
Hamad Alsayed* \\ Faculty of Islamic Studies, Qatar University, 120 Al-Qirawan street, Alwakra, Qatar
}

\begin{abstract}
This paper aims to evaluate the governance of Qatar Central bank (QCB) on Islamic banks (IBs). Related-data will be taken from secondary sources. It is expected that QCB efficiently governs IBs in a way fulfills its unique nature. However, evidence suggests a number of issues in QCB governance towards IBs when looking at various dimensions. In Islamic Financial product dimension, QCB has no clear indications for enforcing its tawaruq-related regulations. This results on the extreme usage of tawaruq by IBs. In the social dimension, while it is suggested by early Islamic economists promoting equity products, such products are very slightly used by IBs in Qatar. The absence of QCB's regulations to promote such social aspects has led to the concentration of debt-based products. In terms of Sharia governance (SG) dimension, a number of issues have been raised such as the absence of cross-boarding regulations and the proper definition for the qualifications of sharia scholars. It is recommended, thus, to enforce tawaruq regulations properly, to create social-oriented regulations, to fix CG related issues discussed in this paper, and to unify Islamic financial contracts among IBs.
\end{abstract}

Keywords: Qatar Central Bank, Sharia governance, Islamic bank 


\section{INTRODUCTION}

\section{Research Background}

It is required for corporate governance (CG) in Islamic financial institutions (IFIs) to have additional layer of governance for ensuring sharia-compliance known as sharia governance (SG). SG is defined by IFSB as "the set of institutional and organisational arrangements through which an IIFS ensures that there is effective independent oversight of Shari 'ah compliance over each of the following structures and processes" (Dusuki. 2015). This includes a number of principles such as setting relevant sharia resolutions, through juristic opinions, operative experts who monitor sharia-compliance for each transaction on a daily basis, internal sharia reviewing body, annual sharia compliance review. Historically, there was no proper definition for sharia governance before this (Dusuki. 2015). While it is the duty of IBs regulators to ensure having sound sharia governance, the current practice of the regulators of IFIs vary in terms of the extent of regulatory support and the availability of friendly-legal frameworks (Dusuki. 2015).

Hasan (2012) has studied the role of regulatory authorities of both Gulf Corporate Countries (GCC) and Malaysia in sharia governance of IFIs. He provides insights on the different types of regulatory authorities in these countries and to what extent they achieve the efficiency in the IF industry. His findings suggest that the sharia governance practiced in Malaysia is more regulated and transparent than the one in GCC. He added that Malaysia is superior on GCC in having a central sharia body, known as Sharia Advisory Counsel, that is involved in both fatwa issuance and dispute resolving.

Hashim et al. (2015) contributes in studying the CG of IFIs from the conventional perspective on the basis of variables such as the size of the board. It has also considered SSB as a main player in IFIs. In a sample of 82 IFIs in GCC and non-GCC, it has been found out that there is a positive relationship between IFIs and board size, directors' independence, and the aspects of environmental, social, and profit in GCC. On the other hand, the size of SSB happened to be in insignificant relationship with the sustainability practices of IFIs. The implication of this is that there is no impact on the size of SSB of IFIs in GCC while there is such impact in non-GCC countries. This study drew attention to the important role of SSB and that further study need to be conducted in evaluating such manner.

In the Qatari context, Nahar (2015) has studied the regulations of QCB pertaining directing SSBs and their internal auditing bodies as well as the monetary policy of QCB. He evaluates the practice of QCB that using Accounting and Auditing Organization for Islamic Financial Institutions (AAIOFI) standards and sharia fiqhi views uncovering a number of issues will be discussed in details later.

That being shown, there is a need to evaluate further different dimensions of the governance of QCB to detect the extent of best can be achieved by IBs in Qatar. 


\section{Research Aim and Objectives}

This paper aims to evaluate the governance of QCB in IB in Qatar. The objectives of this research include

1- Detecting the importance of central banks in governing Islamic financial instructions.

2- Identifying the pros and cons of governance practice of Qatar Central banks.

3- Providing suggestions for improving governance of Qatar Central banks

That being said, the research questions of this paper are as follows.

1 - What is the regulatory importance of Central Banks in governing Islamic financial institutions in general?

2- What dimensions can be identified in the role of central banks as regulators for Islamic financial institutions?

3- What is the current governance framework for governing Islamic banks in Qatar?

4- What are the strengths and weaknesses of sharia governance framework of Qatar Central bank for Islamic banks?

5- What can be suggested for improving the governance of Qatar Central Bank of IFIs?

\section{Significance of the Research}

Although a number of papers discuss the general role of central banks in governing Islamic Financial institutions, a specific study in evaluating the central bank in the Qatari context remains unavailable. Such study is important to provide insights on CG issues occurred between central banks and IFIs in Qatar. The fruits of understanding such issues can be extended to other central banks in either approving or disapproving their practice.

\section{Research Methodology}

Secondary sources related to QCB shall be used. Zawya-based data relevant to Qatari Islamic banks also will be collected. Multiple secondary sources pointed out the pros and cons of current governance practice of QCB in comparison with other central banks. Data obtained from Zawya can provide certain details on Islamic financial products, which will be used to show the implications of corporate governance of IFIs. 


\section{THE RATIONALIZATION OF THE CRUCIAL ROLE PLAYED BY CENTRAL BANKS IN REGULATING ISLAMIC FINANCIAL INSTITUTIONS}

This chapter is to introduce sharia governance as main governance of IFIs. Next, standards setting agencies such as AAIOFI shall be briefly explained as they are used adopted in some times like in Qatar. It then emphasizes the role of central banks in influencing IFIs through the legal and regulatory frame work not only on achieving their financial objectives, but also going beyond that towards socio-economical ones.

\section{Sharia Governance}

As stakeholder interests in Islamic financial institutions differ from those in the conventional, the corporate governance structure should be then articulated in a way that fulfills the rights and obligations of IFIs based stakeholders (Wilson 2012). The profit-sharing investment account, for example, which based on mutual relationship between the clients and banks, suggests further disclosure for tackling the conflict of interest issue that may arise (Wilson 2012). It is thus reasonable to state that corporate governance of IFIs is more sophisticated and fruitful, theoretically at least.

SG framework systematically tackles different issues on the heart of governance (Dusuki. 2015). As shown in the figure below, SG concerns on issues such as approving the products, documenting the contracts legally, and reviewing the transactions, which all centers on SSB and internal sharia audit (Dusuki. 2015). Failure to achieve their work results in reputational sharia risk that may lead clients to distrust their banks.

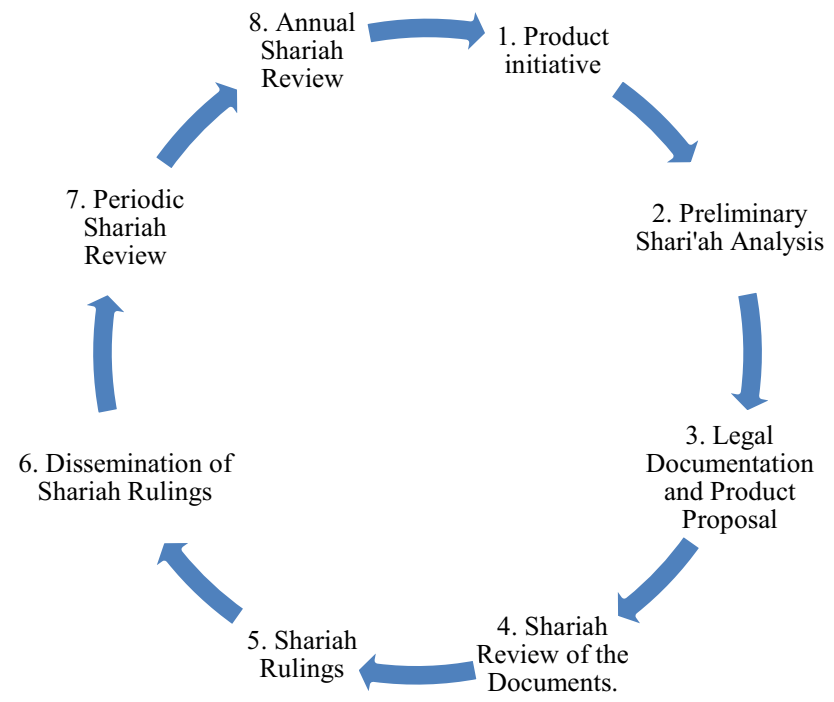

Source: (Dar 2009, cited by Dusuki. 2015, p. 703). 
A unique characteristic that lies on the heart of IFIs is SSBs. Their role varies from one board to another depending on their nature and extent of sharia compliance. Ayub (2007) emphasizes that the degree of sharia compliance and the products relationship to islamic norms are important for the integrity of IFIs. The function of sharia scholars is to assist IFIs in approving products and to ensuring sharia compliancy of financial products during their lifecycle (DeLorenzo 2007). Beyond this, it is noteworthy that the regulators either in bank level or country level as in central banks play a role in determining the scope of authority to SSBs, in addition to legal framework in which the country based on (El-Hawary et al. 2007). Thus, the better the regulatory framework, the better SSBs can be, which aimed to be explored in this paper.

\section{Standards setting Agencies}

International standards setting institutions such as AAIOFI and IFSB play an important role in providing guidelines in sharia, auditing and corporate governance for best practices expected by IFIs, theoretically at least. NawalKasim et al (2013) contributed in comparing different shariah standards, namely, AAIOFI, IFSB and BNM to examine the pros and cons of each. As can be seen from the table below, while there is an advantage discussed by a standard setting institution, the other two remain silent. They conclude that there is a need for a more comprehensive standards related to shariah governance. It is then expected that the regulators of IFIs, in addition to adopting such standards, are considering further regulations than mentioned by such agencies in order to serve stakeholders of IFIs more professionally.

\begin{tabular}{|l|l|l|l|l|}
\hline No & Discussion & AAIOFI & IFSB & BNM \\
\hline 1 & Definiton of Shariah Governance & Not provided & Provided & Not provided \\
\hline 2 & $\begin{array}{l}\text { Independence, competence, } \\
\text { responsibility of shariah supervisory } \\
\text { board }\end{array}$ & Discussed & Discussed & Discussed \\
\hline 3 & Shariah Review and Shariah Audit & Discussed & Discussed & Discussed \\
\hline 4 & Risk management & Not Discussed & Not Discussed & Discussed \\
\hline 5 & Research Function & Not Discussed & Not Discussed & Discussed \\
\hline
\end{tabular}

Table 1: Comparison between different standards of standards settings agencies

\section{Central Banks}

Karim et al. (2013) emphasize the implications the supervisory implications of IF in the sense that the scope of sharia governance can be more difficult depending on the support, the choice, and environment of the regulators. In the United States, for example, there is a constitutional separation of the state from the religion that prevents the involvements of sharia matters. In Sudan or Malaysia, on the other hand, sharia matters face no such restrictions due to the establishments of a central sharia body that is supportive for the existence of Islamic banks in various ways (Karim et al. 2013). 
Shedding the light on central banks, they are different types depending on the established framework of them and the countries they are based on. Briefly, known as nominal approach, there are Islamic central banks in which the whole system becomes Islamic, in having friendly Islamic regulations in particular, such as in Iran and Sudan (Ginena et al. 2015, Hasan 2012, Al-Sayed 2013). However, the rest of central banks operate in the conventional system in which such central banks vary in terms of their supportive friendly regulations and regardless of that, IFIs are required to adopt. These can be divided into three. First, as in Malaysia, its proactive jurisdiction is unique in having an active SSB at the regulatory level while there is no external sharia auditing, and the role of frequent sharia audits by the banking supervisor (Ginena et al. 2015, Hasan 2012, Al-Sayed 2013). Second, as in Oman, the committed approach of sharia governance concerns with the necessary legal framework to recognize, regulate, and supervise Islamic banks in addition to having internal sharia governance arrangements and an SSB ant the bank and regulatory level (Ginena et al. 2015, Hasan 2012, AlSayed 2013). Third, the engaged approach to sharia governance constitutes of the legal framework's recognition to Islamic banking through the enactment of law, the basis of prudent regulatory and supervisory policies and procedures for the industry (Ginena et al. 2015, Hasan 2012, Al-Sayed 2013). Having said this, each jurisdiction differs on articulating their legal framework because while some established laws that permit Islamic banks, others made amendments in the laws to allow the operation of Islamic banks (Ginena et al. 2015). Examples of this type include UAE and Qatar.

Next chapter is the aim of this paper starting with introducing the legal Qatari environment and general characterstics of QCB in general. It is then followed by evaluating QCB's governance for IBs. 


\section{EVALUATING QCB IN GOVERNING IBS IN QATAR}

In order to examine QCB properly, how supportive Qatari law to IFIs shall be explored first. Next, a general description on the role of QCB towards IFIs shall be overviewed. Finally, going to the aim of this paper, evaluating sharia governance of QCB shall be established through a number of dimensions mentioned.

\section{The legal framework of Qatar}

It remains ambiguous to what extent sharia is incorporated in Qatari law concerning Islamic financial contracts. The business transactions are governed by the civil and commercial code, which was modified from the Kuwaiti code (Al-Khatib et al. 2001). The Kuwaiti code goes back to the Egyption civil law, which is originally adopted from French civil code. The whole chain of modifications results in a certain ambiguity of the Qatari law (Ballantyne 2000). This can also explain having elements of both sharia and French civil code in the civil and commercial code of Qatar, as mentioned in a recent study focused in the influence of sharia in Qatari law conducted by Elbarawy (2013). More importantly, the current Qatari law lacks the modern Islamic financial contracts related laws, which create problems for judges in choosing right interpretation (Alsayed 2016) as can be seen from the dispute example discussed later. The absence of such laws led a recent study to conclude that Qatari law is outdated in this regard (Maita 2013).

There are two Qatari regulators for IBS as shown in table (2). Qatar Central bank enjoys high authorities towards IBs because it has been established by the Amiri Decree no. 15/1993 inheriting and replacing Qatar Monetary Agency, the former central banking body (Hasan 2012). In terms of sharia governance, there are two regulatory guidelines provided by QCB and Qatar financial Center (Hasan 2012). The focus here is on the regulations of QCB, known as Instructions to Banks (IB) (Hasan 2012). Part 7 of it is concerned on instructing particularly IFIs (Hasan 2012). Further details will be discussed next. 


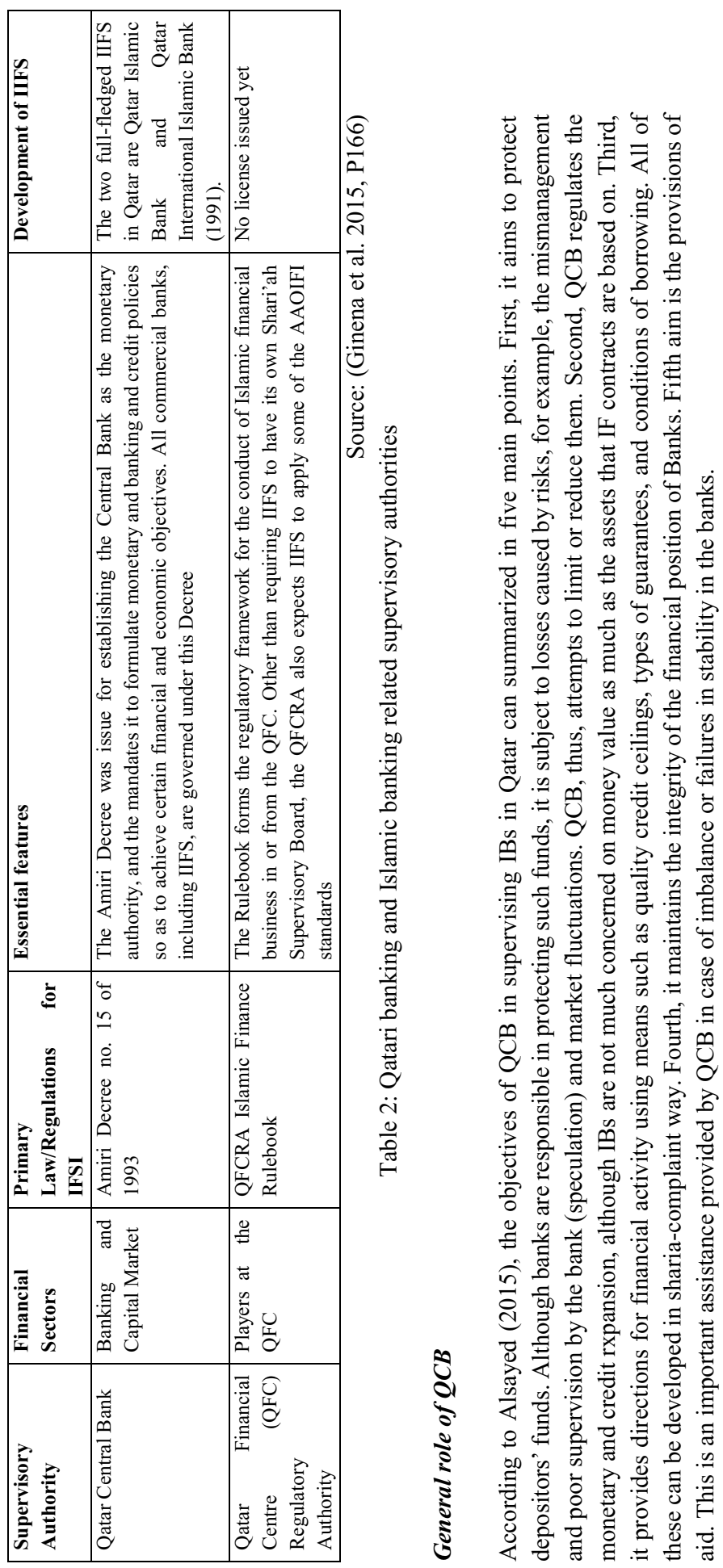


Although these objectives are in-line with the sharia in fulfilling the financial sector, it is, however, does not provide particular socio-economics objectives to direct IBs towards achieving social objectives that early Islamic economists were concerned about (Asutay 2007). Furthermore, according to Kahf et al. (2014), QCB still lacks IF friendly products to fulfil the need of IFIs in case of financing as last resort as will be discussed later.

QCB has adopted Basal, IFRS and IFSB accounting standards, and AAOIFI governance standards, particularly, for Islamic banks ${ }^{1}$. The focus here will be three dimensions, namely, Islamic financial products, social, and sharia governance dimensions.

\section{Islamic Financial Products dimension}

There are different issues related to how supportive QCB for IFIs in sharia-complaint products. From one side, sharia-complaint products from QCB for the financier as last resort are missing. From another, QCB has not unify or restrict the diversity of different Islamic financial contracts among IBs in Qatar leading indirectly to misunderstanding issues in Qatari courts as shown in the dispute example. As the regulatory framework established in QCB is conventional based rather than Islamic-based, QCB is only risk and profit focused rather than ensuring the unity and smoothness of Islamic financial products in different Islamic banks in Qatar.

Kahf et al. (2014) has pointed out that QCB lacks shariah-complaint instruments for improving liquidity management, in particular, for financing as last resort and interbanking. As such, they attempted to develop theoretically such instrument that can be sharia complaint and in-line with national law of Qatar. They also have surveyed the experience of other central banks such Bahrain and Malaysia in developing such instrument that QCB is in serious need. This shows the absence of the role of QCB in supporting sharia-complaint product for IFIs in the case of last resorting.

Second, the unity of IFCs among IBs is a cause of numerous issues. Above all, the hybrid Islamic financial contracts that are characterized as sophisticated contracts are difficult to understand for non-IF specialists including judges in courts ${ }^{2}$. Having such contracts have led to different interpretations made by judges in Qatari courts.

Alsayed (2016) has analyzed a Qatari-based case involves Ijarah muntahiah bittamleek (IMBT) (lease to own) contract, a hybrid Islamic financial contract in which the client defaults due to the failure to fulfill this obligations. In the case he explores, the judge interprets IMBT contract as promise of sale because the contract does not fall into the provisions of Law No. 4/2008 concerning the Rent of Buildings and as such, the judge

\footnotetext{
${ }^{1}$ This is what I was told in an interview with an expert from QCB during my Master's dissertation.

${ }^{2}$ This is another point that the expert of QCB I interviewed has emphasized strongly.
} 
has refused looking at an issue that is not under the judge's specialty. In supporting this, the judge evidenced that IMBT reflects the prophetic prohibition of two sales on one without referring to a particular Islamic financial code. The judge's' understanding for the contract led to this interpretation, which is contradicting what AAIOFI made lawful on standard no. 9. This suggests inconsistency related issue between IBs in Qatar and Qatari courts. Such conclusion is expected to be avoided if Islamic financial contracts are united and documented in similar way that prevents the confusion of understanding. The unity of Islamic financial contracts is expected to be taken into account under the Qatari law if it comes from Qatar Central Bank. This shows an issue of inconsistency of interpretation between sharia scholars' interpretation and judges under Qatari law, which QCB can be partially blamed for indirectly.

\section{Social dimension}

A number of maqasid-oriented literature emphasizes that IF based products should encourage equity based such as musharaka and mudaraba rather than debt-based such as murabaha and tawaruq. Asutay (2007), for example, drew attention to the socioeconomic failures of IF in disintegrating Islamic maxims on the products provided by IBs.

However, according to Asutay (2007), the current practice of Qatari IBs seems to be a part of this socio-economic failure. Based on data collected from Zawya, table (3) demonstrates that the total assets of musharaka, mudaraba and murabaha in, as an example, Masraf alrayyan between 2010 and 2014. The total assets of debt-based products are doubled multiple times and superior to equity-based ones. This raises questions over the regulatory role in directing the usage of IF products in socioeconomics friendly products. 


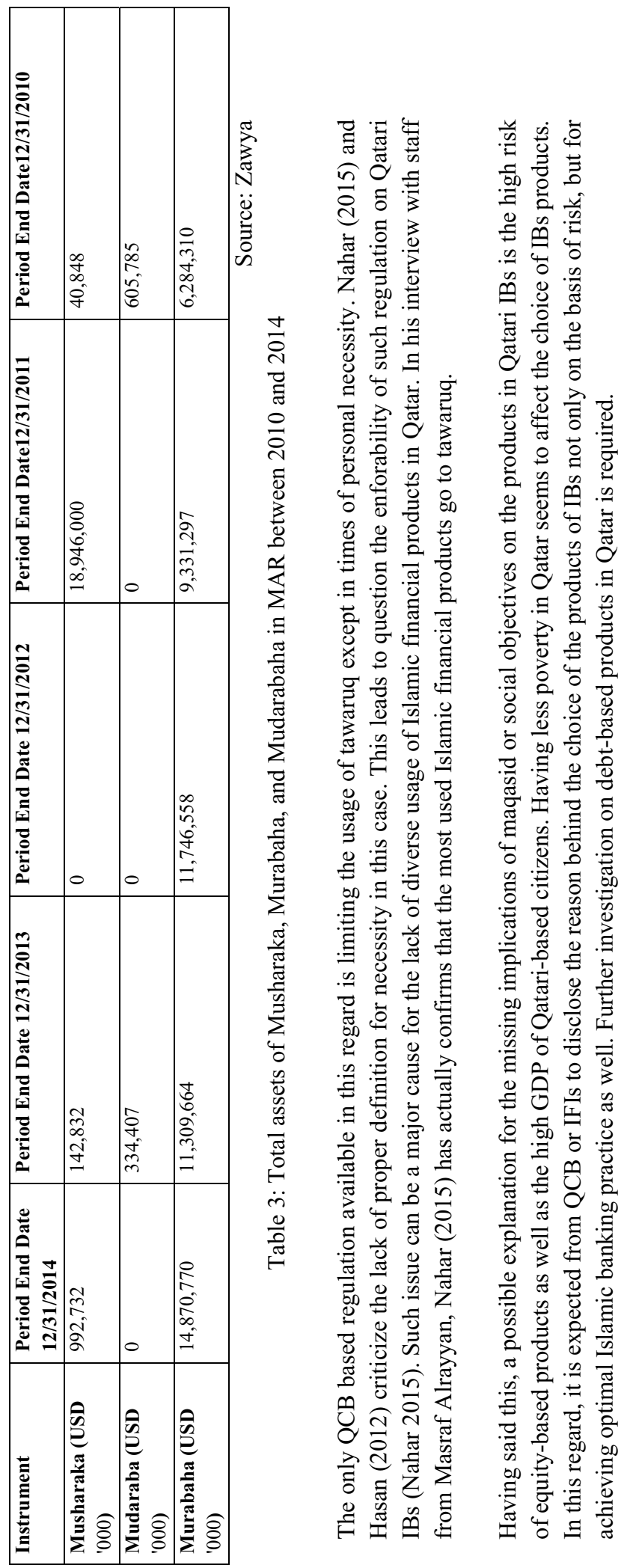




\section{Sharia Governance dimension}

Although AAIOFI governance standards are adopted by QCB, there is a number of issues has been raised. First, sharia board members are restricted from receiving credit facilities for commercial purposes, but not personal matters. It is noteworthy that this restriction is not only for SSB members, but also for the members of board of directors (Nahar 2015). It has been questioned why not expanding this restriction further to personal purposes. A possible explanation is that QCB would like to provide a chance for such members to get access for financing in the event of serving in all boards (Hasan 2012, Ginena et al. 2015).

Second, although QCB requires IFIs to have qualified sharia members, it has not defined such qualifications (Nahar 2015, Ginena et al. 2015). Given his sharia background, Nahar (2015) suggested certain qualities in sharia scholars sitting in SSBs. These are the fiqhi ability (malakah fiqhiyyah) in understanding scholarly opinions, the ability of analogical thinking for identifying similar cases in past and future, the quality of smartness, quick noticing and understanding the life of people. These qualities are also mentioned by AAIOFI, but Nahar (2015) has also added the following qualities, namely, having strong personality for not being tricked or forced in non-sharia complaint manner, and learning English language.

Third issue is to have a minimum of two sharia board members (Ginena et al. 2015, Nahar 2015). Nahar (2015) criticizes choosing a minimum of two members rather than three because in the case of dispute in opinions, there will be no third person to settle between the two in choosing the final opinion, which is is required for proper management's point of view.

Fourth, Nahar (2015) raises some issues related to the regulation of having sharia body auditing in IFIs. The issues he raised are the absence of precise definition for the qualifications of sharia auditors and supervisors as well as the lack of identifying a minimum number for sharia auditors. As for the qualifications, Nahar (2015) has referred to the qualifications mentioned for the members of SSBs. Regarding the number of sharia auditors, he suggested that such matter is subject the size of the bank.

That being said, there are a number of non-discussed issues by QCB. One of the issues pointed out by AAIOFI in sharia standard no. 29 on 3/5 but not referred to by QCB is the fact that it is not allowed for IFIs to ask for fatwa issuance from other than their SSBs (Ginena et al. 2015). This can play an important role in determining the choice of products to be more in-line with the maqasid, rather than being market and profit oriented.

Second, QCB has not limited the number of cross-boarding for the members of SSBs, unlike the Malaysian regulator (Ginena et al. 2015). A possible explanation for 
overlooking this issue by QCB is the slim chance of impact on this (Ginena et al. 2015) given the defined role of the members of SSB. Also, it is possible that in the regulator's view the financing given for the members do not reach the level that creates independence issue (Ginena et al. 2015).

Overall, it can be seen that a number of the issues discussed are due to the usage of abstract language that can lead to weak sharia governance practices. 


\section{CONCLUSION}

This paper aims to evaluate the governance of Qatar Central bank (QCB) on Islamic banks (IBs). The methodology used is, mainly, the secondary sources and Zawya. It is expected that QCB efficiently governs IBs in a way fulfills its unique nature. This unique nature can be seen from sharia governance of IFIs represented by SSBs. Their role is important in the stability of IFIs and in ensuring the avoidance of reputational and sharia risk. This requires extra consideration in the regulations given to IFIs. However, evidence suggests a number of issues regarding QCB governance towards IBs when looking at various dimensions.

In Islamic Financial product dimension, QCB has not defined clearly the personal necessity for allowing the usage of tawaruq in its regulations. This possibly results on the extreme usage of tawaruq by IBs. As such, there are no clear indications for enforcing its tawaruq-related regulations. In the social dimension, there is lack of diversity of islamic financial products as the concentration is on the usage of tawaruq, rather than promoting for example equity based products.

In terms of Sharia governance (SG) dimension, a number of issues have been raised such as the absence of cross-boarding regulations and the proper definition for the qualifications of sharia scholars. It is recommended, thus, to enforce tawaruq regulations properly, to create maqasid-oriented regulations, to fix the CG issues discussed in this paper and to unify Islamic financial contracts among IBs in Qatar

The limitation of this paper is the lack of quantitative evidence that can be strong indications for the issues raised. Another limitation is restricting the research in the Qatari context with sharia governance focusing. Future research are advised to apply the research of CG of IFIs in MENA region through productive comparisons and optimal practices of CG. 


\section{REFERENCES:}

AAIOFI, (2015) Accounting, Auditing and Governance Standards for Islamic Financial Institutions. Manama, Bahrain, Accounting and Auditing Organization for Islamic Financial Institutions.

Al-Khatib, F. and Al-Abdulla, S. (2001) The State of Qatar: A Financial and Legal Overview. Middle East Policy. [Online] 8 (3), 110-125. Available at: doi:doi:10.1111/1475-4967.00031 (Accessed: 31 August 2016).

Al-Sayed, H. (2013) [i] A Study on The Development and Analysis of Investment Tools in Islamic Banks[/i]. Ph. D. University of Wales, Lampeter.

Alsayed, H. (2016) [i] Explorative study on the extent of consistency between Islamic Financial Contracts and Qatari laws through a Qatari-court-based dispute analysis involved an Islamic financial contract[/i]. MSc. University of Durham.

Asutay, M. (2007) Conceptualisation of the Second Best Solution in Overcoming the Social Failure of Islamic Banking and Finance: Examining the Overpowering of Homoislamicus by Homoeconomicus. IIUM Journal of Economics and Management. 15 (2), 167-195.

Ayub, M. (2007) Understanding Islamic finance. Hoboken, NJ, John Wiley \& Sons.

Ballantyne, W. (2000) Essays and addresses on Arab laws. Richmond, Surrey, Curzon.

DeLorenzo, Y. (2007) Shari'ah Compliance Risk. Chicago Journal of International Law. 7 (2), 1-13.

Dusuki., A. (2015) Islamic financial system: Principles and Operations. 5th edition. Kuala Lumpur, International Shari'ah Research Academy for Islamic Finance (ISRA).

Elbarawy, H. (2013) Ta'athir Alsharia Alislamiah ala Alqanon Almadani AlQatari: Dirasa muqarana (The influence of Islamic Shari'a on Qatar's civil law: A comparative study). International Review of Law. [Online] 21-21. Available at: doi:10.5339/irl.2013.cl.2 (Accessed: 31 August 2016).

El-Hawary, D., Grais, W. and Iqbal, Z. (2007) Diversity in the regulation of Islamic Financial Institutions. The Quarterly Review of Economics and Finance. [Online] 46 (5), 778-800. Available at: doi:10.1016/j.qref.2006.08.010.

Ginena, K. and Hamid, A. (2015) Foundations of Shari'ah governance of Islamic banks. Hasan, Z. (2012) Shari'ah Governance in Islamic Banks. Edinburgh, Edinburgh University Press.

Hashim, F., Mahadi, N. and Amran, A. (2015) Corporate Governance and Sustainability Practices in Islamic Financial Institutions: The Role of Country of Origin. Procedia Economics and Finance. [Online] 3136-43. Available at: doi:10.1016/s2212-5671(15)01129-6.

Kahf, M. and Hamadi, C. (2014) An Attempt to Develop Sharī'ah Compliant Liquidity Management Instruments for the Financier of Last Resort: With Reference to Qatar Development Plan. Islamic Economic Studies. 22 (1).

Karim, R. and Archer, S. (2013) Islamic Finance: The New Regulatory Challenge, 2nd Edition. John Wiley \& Sons. 
Maita, A. (2013) [i]Development of a Commercial Arbitration Hub in the Middle East:

Case Study - The State of Qatar[/i]. Ph. D. Golden Gate University School of Law,

Nahar, N. (2015) Alsairafa Alislamiah fi Dawlat Qatar (Islamic Banking in the State Islamiah fi Dawlat Qatar 